\title{
Análise da conduta das revendedoras de gasolina comum nas capitais da região Nordeste
}

\author{
Rosangela A. S. Fernandes ${ }^{1}$ \\ Kamila Gabriela Jacob²
}

\begin{abstract}
Resumo: O objetivo do artigo é a verificação de indícios econômicos de carteis na revenda de gasolina comum nas capitais da região Nordeste, de janeiro de 2010 a dezembro de 2015. Os resultados dos índices concorrenciais de preços indicaram que não houve concorrência entre as revendedoras. A maioria das margens de comercialização apresentaram suave tendência ascendente. As correlações entre as margens e o coeficiente de variação mostraram que, em Salvador, Fortaleza, São Luís e João Pessoa, as elevações nas margens podem estar associadas a menor variância dos preços, sugerindo que os postos estariam adotando conduta uniforme nessas capitais.
\end{abstract}

Palavras-chave: gasolina comum, cartel, Nordeste.

\section{Classificação JEL: D41, C30, C36.}

Analysis of conduct of common gasoline resellers in the capital of the northeast region

\begin{abstract}
The aim of the paper was to determine whether there are economic evidence of cartels in the retail common gasoline in the capitals of the Northeast region, from January 2010 to December 2015. The results of the competitive price indices indicated that there was no competition between dealers. Most sales margins showed mild upward trend. Correlations between the banks and the coefficient of variation showed that in Salvador, Fortaleza, São Luís and João Pessoa, the increases in margins may be associated with less variance in prices, suggesting that the posts could be adopting uniform conduct in these capitals.
\end{abstract}

Key-words: Common gasoline, cartel, Northeast.

JEL Classification: D41, C30, C36.

1 Doutora em Economia Aplicada pela Universidade Federal de Viçosa. Professora Adjunta III pela Universidade Federal de Ouro Preto - Campus Mariana. E-mail: roaeconomista@yahoo.com.br

2 Mestre em Economia Aplicada pela Universidade Federal de Viçosa. Professora Substituta pela Universidade Federal de Ouro Preto - Campus Mariana. E-mail: kamila.g.jacob@gmail.com 


\section{Introdução}

A revenda de combustíveis líquidos, especialmente de gasolina comum, representa o maior número de casos sobre denúncias envolvendo a investigação de carteis junto ao Sistema Brasileiro de Defesa da Concorrência. Atualmente, o combate às condutas cartelizadas é um dos principais focos de atuação da Secretaria de Direito Econômico (SDE), com destaque para os setores de combustíveis. De acordo com Júnior et al (2008), no Brasil, até em municípios com grande número de concorrentes, os proprietários de postos e associações de proprietários são frequentemente alvos de investigações de práticas de carteis.

É importante salientar também que as características microeconômicas desse mercado propiciam o comportamento anticoncorrencial por parte dos postos revendedores: a homogeneidade do produto ofertado, a demanda inelástica em relação aos $\operatorname{preços}^{3}$, a estrutura de custos semelhantes e as barreiras regulatórias que dificultam a entrada de novos concorrentes. Adicionalmente, a atuação ativa dos sindicatos e associações viabiliza a uniformização ou a coordenação de condutas comerciais entre os filiados.

Nesse contexto, torna-se relevante verificar as possíveis evidências de formação horizontal de cartel entre os postos revendedores de gasolina comum nos diferentes mercados expressivos geográficos. No Brasil, há vários trabalhos na literatura que buscaram investigar a formação de carteis na revenda de combustíveis utilizando-se diferentes metodologias: Vasconcelos e Vasconcelos (2005, 2008, 2009), Freitas (2010), Fetter (2012) e Silva et al. (2014).

Vasconcelos e Vasconcelos (2005) utilizaram uma metodologia adaptada de Gülen (1996) para investigar a dinâmica histórica de preços no varejo de gasolina sob a hipótese de paralelismo como filtro para possíveis cartéis. Vasconcelos e Vasconcelos (2008) elaboraram indicadores de colusão por meio de modelos de análise de variância, ARCH e GARCH, para analisar a revenda de gasolina no Brasil. Em 2009, estes autores também simularam os dados de preços de varejo para filtrar uma inconsistência no comportamento de agentes derivada de comportamento colusivo. Freitas (2010), a partir de uma metodologia georreferenciada, construiu um filtro de detecção de indícios de cartel na revenda de gasolina em Porto Alegre. Fetter (2012), a partir das hipóteses de marcadores de colusão sugeridas por Harrington Jr. (2005), buscou identificar padrões em série de preços de gasolina comum que poderiam aderir aos pressupostos de colusão. Para tal, utilizou um painel de dados dinâmicos em municípios brasileiros, comparando os resultados com aqueles encontrados para os 10 municípios com um histórico de cartéis condenados pelo Conselho Administrativo de Defesa

\footnotetext{
$\mathrm{Na}$ literatura existem vários trabalhos empíricos que evidenciaram que a demanda por gasolina comum no Brasil é inelástica em relação a seu preço, no curto e no longo prazos, mesmo com o álcool hidratado como seu substituto. Para mais informações ver os trabalhos de Burnquist e Bachi (2002), Alves e Bueno (2003), Roppa (2005), Nappo (2007), Diehl et al (2007), Schunemann (2007)..
} 
Econômica (CADE). Silva et al. (2014) analisaram o problema da assimetria nos preços dos postos de gasolina nos municípios brasileiros. Para tanto, utilizaram modelos Threshold, sobre o pressuposto de que a assimetria pode servir de filtro de possíveis ações anticompetitivas.

Assim como os trabalhos supracitados, esta pesquisa teve como objetivo verificar se existem indícios econômicos de práticas de conduta cartelizada na revenda de gasolina comum. Entretanto, foram escolhidas, como foco de análise, as nove capitais da região Nordeste do país, no período de janeiro de 2010 a dezembro de 2015. Optou-se por esses mercados relevantes geograficamente pelo fato de que eles, em sua maioria, já foram alvos de denúncias e investigações sobre condutas anticompetitivas ${ }^{4}$. Além disso, há evidências de que possivelmente nos municípios da região Nordeste, as revendedoras apresentam indícios de conduta colusiva. Júnior et al (2008), ao analisar a competição no mercado de gasolina nos municípios do Brasil, de janeiro de 2007 a abril de 2008, verificaram a existência de correlação negativa e estatisticamente significativa entre a margem de comercialização e o coeficiente de variação de preços da gasolina comum para a região Nordeste. Segundo os autores, a menor variabilidade dos preços da gasolina nos postos de um município, associada à sua maior margem bruta, é indício de práticas anticompetitivas.

\section{Referencial teórico}

\subsection{Defesa da concorrência e o cartel}

A investigação de condutas anticompetitivas é uma das prioridades do Sistema Brasileiro de Defesa da Concorrência. As condutas anticoncorrenciais com possíveis impactos anticompetitivos precisam ser avaliadas pelas autoridades antitrustes, a fim de adotar punições às condutas lesivas na competição de mercado. Entretanto, é importante salientar que a lei antitruste busca reprimir o abuso de

\footnotetext{
Em 2007, a SDE, em cooperação com a SEAE, a Polícia Federal e o Ministério Público do Estado da Paraíba deflagraram operação (Operação "Pacto 274”) em João Pessoa e Recife para obter provas de cartel no mercado de revenda de combustíveis (CADE, 2014). Em 2013, o CADE condenou o Sindicato do Comércio Varejista de Derivados de Petróleo no Estado do Piauí e uma pessoa física por influenciarem condutas comerciais dos postos associados. As multas aplicadas somaram cerca de R 6 milhões (CADE, 2013). Em 2014, a Superintendência-Geral do CADE instaurou um processo administrativo para apurar suposta prática de cartel nos mercados de distribuição e revenda de combustíveis na região metropolitana de São Luís, no Maranhão. Na denúncia, segundo o Ministério Público em 2011, os postos fixavam preços de revenda dos combustíveis sob orientação do Sindicato de Combustíveis. Nesse ano, também foi instaurado um processo administrativo (PA n ${ }^{\circ}$ 08700.000625/2014-08) para apurar supostas práticas de cartel e de limitação à concorrência no mercado de revenda de combustíveis na cidade de Natal, no Rio Grande do Norte. O procedimento foi contra 19 postos de gasolina, o Sindicato do Comércio Varejista de Derivados do Petróleo do Estado do Rio Grande do Norte - Sindipostos/RN, a Petrobras Distribuidora S/A e sete pessoas físicas (CADE, 2014).
} 
poder de mercado porque ele é gerador de ineficiências, portanto, não deve proibir atos/condutas que gerem ganhos de eficiências líquidos, pois, se o fizer, gerará ineficiências tão mais significativas do que as que visa combater.

Dentre as condutas consideradas lesivas à concorrência, cita-se os acordos de exclusividade, a discriminação de preços, a venda casada, a recusa de negociação, a prática de preços predatórios e os carteis. Tais práticas anticompetitivas são definidas como restrições verticais e horizontais. No primeiro caso, as empresas usam o seu poder de mercado para obter ganhos econômicos em detrimento de outras empresas situadas em etapas diferentes da cadeia produtiva; já as restrições horizontais, são caracterizadas principalmente por colusão entre empresas atuantes no mesmo mercado, de forma a agir coordenadamente para aumentar seus ganhos individuais.

Especificamente, entre as condutas horizontais adotadas por empresas que atuam na revenda de combustíveis, merece destaque a prática de cartel, um acordo comercial entre as empresas, visando à distribuição do mercado entre elas, com a finalidade de determinar os preços e limitar a concorrência. $\mathrm{O}$ cartel pode ser definido como um acordo entre as empresas que aumentam lucros, promovendo perdas de bem-estar social, pois as firmas desviam do equilíbrio competitivo em razão de sua estrutura de mercado (FREITAS, 2010). De acordo com Maggi (2010), o cartel é um acordo horizontal e, a priori, está sujeito à análise sobre os benefícios ou os prejuízos gerados ao mercado. Porém, a sua natureza faz com que haja prejuízos ao mercado, uma vez que o objetivo é a elevação de preços, direta ou indiretamente. Logo, os seus efeitos sobre o bem-estar social são negativos.

O cartel é uma associação de firmas que coordenam suas atividades tendo em vista o aumento do lucro. De acordo com Carlton \& Perloff (1994, p.175): "In any market, firms have incentive to coordinate their production and pricing activities to increase etheir collective and individual profits by restricting market output and raising the market price. $\mathrm{Na}$ association of firms that explicit agrees to coordinate its activities is called cartel".

Nessa estrutura de mercado, o objetivo de cada firma é a maximização do lucro. Para tal, as firmas coordenam as suas ações visando fixar o preço ou a quantidade no mercado. Para que isso seja possível, a coordenação deve possuir, no mercado, um pequeno número de empresas ou um grande número de empresas com participações divergentes. Desse modo, ocorrerá um poder de mercado concentrado nas mãos de poucas empresas. $\mathrm{O}$ cartel abrange acordos horizontais entre agentes que concorrem em um mercado, esses utilizam de práticas concertadas com as variáveis econômicas que afetam a concorrência, como os preços, as quantidades, as condições de pagamentos, as divisões geográficas do mercado, entre outras. Os membros do cartel se beneficiam do aumento de seus lucros, porém, há uma redução do nível de bem-estar social.

De acordo com a Secretaria de Direito Econômico (2009), dentre as condutas anticompetitivas, o cartel é a mais grave lesão à concorrência. Os cartéis prejudicam gravemente os consumidores ao elevar preços e restringir a oferta, tornando os bens 
e serviços mais caros ou indisponíveis. O poder de um cartel de limitar artificialmente a concorrência também traz prejuízos à inovação, uma vez que impede que outros concorrentes aprimorem seus processos produtivos e lancem novos e melhores produtos no mercado. Consequentemente, há perdas de bem-estar do consumidor e, no longo prazo, perda da competitividade da economia como um todo.

Para Forgioni (2005), as características existentes no mercado que o tornam predisposto à formação de cartel são: (i) número reduzido de agentes atuando; (ii) homogeneidade dos produtos; (iii) baixa elasticidade preço da demanda; (iv) existência de barreiras à entrada; (v) mercados em retração; (vi) concentração de mercado.

Segundo Carlton \& Perloff (1994), os cartéis têm maior facilidade de se formar em mercados em que o número de firmas que controlam grande parte deles é restrito, em que a demanda é inelástica em relação ao preço, e em que se verificam barreiras à entrada. Desse modo, as poucas firmas terão facilidade de se comunicarem e traçarem entre si estratégias de aumento dos lucros. A demanda inelástica torna os consumidores menos sensíveis às alterações nos preços, assim, os aumentos nesses preços resultam em rendas maiores para os ofertantes. As barreiras à entrada permitirão que essa renda se perpetue, não permitindo que outros agentes entrem no mercado em busca dos lucros extraordinários.

O sucesso da conduta cartelizada depende de elementos organizacionais, como a distribuição do poder do cartel, a sofisticação dos mecanismos de detecção e a intimidação da trapaça, a estrutura de votos, a habilidade de criação de barreiras à entrada, o progresso tecnológico, dentre outros. Paralelamente, elementos exógenos à indústria também são relevantes, como a regulamentação governamental e o enforcement antitruste. Além disso, o sucesso do cartel depende de determinantes peculiares, como a velocidade de aprendizado da organização sobre o desenho do cartel, os custos iniciais de criação do cartel bem como a reputação de seus membros (FREITAS, 2010).

Especificamente, o setor de combustíveis líquidos lidera o ranking nos inquéritos administrativos envolvendo a formação de carteis no Brasil. A Secretaria de Direito Econômico - SDE acumula cerca de 120 investigações de cartel de revendedores varejistas de combustíveis. Esse número representa, aproximadamente, um terço do total de casos em andamento, entretanto, muitas dessas investigações dependem da iniciativa de denunciantes, para maiores averiguações em virtude da dimensão do Brasil.

Entre as características do mercado de combustíveis que viabilizam o comportamento colusivo cita-se: a homogeneidade do produto ofertado e a pequena diferenciação em serviços; as estruturas de custos semelhantes; a existência de elevada transparência de preços; o histórico de tabelamento governamental de preços no setor; as associações patronais bem organizadas; os contratos verticais de exclusividade; as barreiras à entrada; a ausência de substitutos próximos bem como a demanda inelástica em relação ao preço.

A formação de cartel envolvendo os revendedores de combustíveis líquidos pode ocorrer, por exemplo, quando as empresas, que deveriam concorrer entre si, 
passam a determinar um preço ou intervalos para esse preço ser praticado junto aos consumidores. Nesse caso, o condutor percebe que os preços são praticamente os mesmos em todos os postos de combustíveis. Assim, suspeita-se que exista um acordo entre os revendedores.

\section{Metodologia}

Neste artigo, buscou-se verificar se há indícios econômicos de cartelização nos mercados relevantes de revenda de gasolina comum para as nove capitais nordestinas, no período de janeiro de 2010 a dezembro de 2015. Para tal, utilizou-se uma metodologia semelhante àquela sugerida pela Agência Nacional de Petróleo, Biocombustíveis e Gás Natural (ANP) e pela Secretaria de Acompanhamento Econômico (SEAE):

(i) Mensuração e análise da evolução das margens e coeficientes de variação de preços;

(ii) Estimação e análise das correlações entre a margem de comercialização na revenda e o coeficiente de variação dos preços.

Entretanto, uma análise prévia dos resultados dos Índices Concorrenciais de Preços- ICP (também conhecido na literatura por coeficiente de variação) foi realizada, com o intuito de descartar mercados relevantes geográficos em que a concorrência possivelmente encontra-se mais expressiva, conforme a interpretação desse índice, ou seja, para resultados em que o ICP é superior a 1\%. Segundo Freitas e Neto (2011), o ICP é uma ferramenta estatística chamada de coeficiente de variação - CV. A sua aplicação no mercado de combustíveis se dá a fim de verificar o nível de concorrência entre os postos.

O ICP, ou (coeficiente de dispersão de preços), pode ser obtido a partir da mensuração do índice abaixo:

$$
I C P=\frac{\text { Desviopdrv } v_{i}}{\operatorname{Pr} \text { médior } v_{i}}
$$

Em que Desviopdrv $v_{\mathrm{i}}$ é o desvio padrão dos preços da gasolina na revenda em cada capital nordestina e Prmédiorv é o preço médio da gasolina na revenda em cada capital nordestina.

Conforme a metodologia sugerida pelo Centro Integrado de Pesquisas (CIP) do Instituto de Ciências Econômicas, Administrativas e Contábeis - ICEAC da Universidade Federal do Rio Grande - FURG, quanto mais próximo de zero for seu valor, menor a concorrência entre os postos de combustíveis. Para $I C P \leq 1 \%$ : praticamente não existe concorrência e quando $I C P>1 \%$ existe concorrência (Tabela 1). 
Tabela 1: Características do Índice Concorrencial de Preços - ICP

\begin{tabular}{c|c|c|c}
\hline Valor ICP & Denominação & Significado & Concorrência \\
\hline $\mathrm{ICP} \leq 1 \%$ & Área de não-concorrência & $\begin{array}{c}\text { Os preços estão } \\
\text { fortemente alinhados }\end{array}$ & $\begin{array}{c}\text { Praticamente não } \\
\text { existe concorrência }\end{array}$ \\
\hline $\mathrm{ICP}>1 \%$ & Área de concorrência & $\begin{array}{c}\text { Os preços não estão } \\
\text { fortemente alinhados. }\end{array}$ & Existe concorrência \\
\hline
\end{tabular}

Fonte: CIP/ICEAC da FURG.

A margem de comercialização na revenda foi calculada para todas as “i” capitais nordestinas em análise, no período de janeiro de 2010 a dezembro de 2015, conforme a expressão:

$$
M g v=\frac{P v-P d}{P v}
$$

Em que Mgv é a margem bruta de comercialização na revenda;

Pv é o preço da gasolina comum nos postos revendedores;

Pd é o preço da gasolina comum nas distribuidoras.

A análise das margens de comercialização oferece informações a respeito da magnitude das parcelas de cada setor do mercado. Evidências de margens de comercialização elevadas ou crescentes sinalizam ineficiência do mercado, a menos que essa estivesse associada à inclusão de novos serviços que resultariam em melhorias na qualidade final do produto.

Segundo Azevedo e Politi (2008), dentre os testes sugeridos pela Secretaria de Acompanhamento Econômico (SEAE) para verificar a ocorrência de conduta colusiva, o que melhor separa as hipóteses de concorrência perfeita e o cartel é o que estima a correlação entre a margem de revenda e a variância de preços, pois se esperam resultados opostos para cada uma das hipóteses.

Para obter o coeficiente de correlação entre a margem de comercialização na revenda e o coeficiente de variação dos preços de gasolina comum em cada uma das capitais da região Nordeste, estimou-se a equação (3) abaixo:

$$
M g r v_{i t}=\beta_{0}+\beta_{1} I C P_{i t}+\varepsilon_{i t}
$$

Em que $\mathrm{Mgrv}_{\text {it }}$ é a margem de comercialização na revenda de gasolina comum em cada uma das capitais "i” em análise; $\beta_{0}, \beta_{1}$ são os coeficientes a serem estimados; $I C P_{i t}$ é o coeficiente de variação de preços da gasolina nos postos das "i" capitais analisadas, calculado anteriormente como índice concorrencial de preços e $\varepsilon_{i t}$ é o termo de erro aleatório. 
A equação (3) acima foi estimada a partir do Método dos Mínimos Quadrados Ordinários, a partir da utilização do Softwware Eviezws 7.0.

Para $\beta_{1}>0$, existe correlação positiva entre a margem de comercialização na revenda e o coeficiente de dispersão dos preços da gasolina comum. Nesse caso, trata-se de evidência de concorrência no mercado analisado, uma vez que, enquanto a margem aumenta, o mesmo ocorre com o coeficiente de variação na revenda.

Para $\beta_{1}<0$, existe correlação negativa entre a margem de comercialização na revenda e o coeficiente de dispersão dos preços da gasolina comum. Nesse caso, o coeficiente de variação e a margem estariam se comportando de maneira suspeita: enquanto um diminui, o outro aumenta, o que seria indício de cartel.

\subsection{Fonte de dados}

Para a realização dessa pesquisa, utilizou-se os dados mensais dos preços da gasolina comum na revenda e nas distribuidoras, bem como os seus respectivos desvio-padrão dos preços mensais das revendedoras, de janeiro de 2010 a dezembro de 2015. Todos os dados foram obtidos no banco de dados do site da ANP- Levantamento de Preços.

\section{Resultados e discussões}

Conforme salientado anteriormente, a revenda de combustíveis é frequentemente alvo de acusações de práticas de conduta cartelizada, com um expressivo número de denúncias junto ao Sistema Brasileiro de Defesa da Concorrência - SBDC. Entretanto, Azevedo e Politi (2008), ressaltam que, em razão da pequena dimensão geográfica dos mercados relevantes na revenda de combustíveis, pode existir custos de investigação superiores ao benefício social decorrente da intervenção. Possivelmente, isso ocorre em razão da elevada probabilidade da denúncia não resultar em provas de conduta uniforme entre concorrentes, e/ou pelo fato de os custos sociais inerentes ao cartel não serem muito altos em razão do tamanho do mercado. Além disso, adicionam que, por comercializarem produtos homogêneos e recorrerem às mesmas fontes de insumos, pode ocorrer preços semelhantes em postos de combustíveis, mesmo na ausência de cartel.

Mediante esse contexto, nesta pesquisa buscou-se verificar a existência de indícios econômicos de cartelização nos mercados relevantes de revenda de gasolina comum para as nove capitais nordestinas, no período de janeiro de 2010 a dezembro de 2015.

A Tabela 2 reporta as informações a respeito das médias mensais dos Índices Concorrências de Preços para as capitais nordestinas, bem como as suas respectivas conclusões sobre a concorrência, de 2010 a $2015^{5}$.

\footnotetext{
5 Informações sobre os índices mensais para este período encontram-se disponíveis no Anexo A.
} 
Tabela 2: Índices Concorrenciais de Preços (médias mensais) nas capitais da região Nordeste

\begin{tabular}{c|c|c|c|c|c|c|c}
\hline Capitais & 2010 & 2011 & 2012 & 2013 & 2014 & 2015 & $\begin{array}{c}\text { Conclusão sobre } \\
\text { a concorrência }\end{array}$ \\
\hline Maceió & $0,019 \%$ & $0,018 \%$ & $0,020 \%$ & $0,024 \%$ & $0,025 \%$ & $0,030 \%$ & $\begin{array}{c}\text { Praticamente } \\
\text { não existe }\end{array}$ \\
\hline Salvador & $0,031 \%$ & $0,031 \%$ & $0,030 \%$ & $0,032 \%$ & $0,029 \%$ & $0,034 \%$ & $\begin{array}{c}\text { Praticamente } \\
\text { não existe }\end{array}$ \\
\hline São Luís & $0,033 \%$ & $0,042 \%$ & $0,030 \%$ & $0,034 \%$ & $0,019 \%$ & $0,027 \%$ & $\begin{array}{c}\text { Praticamente } \\
\text { não existe }\end{array}$ \\
\hline João Pessoa & $0,038 \%$ & $0,037 \%$ & $0,028 \%$ & $0,026 \%$ & $0,024 \%$ & $0,035 \%$ & $\begin{array}{c}\text { Praticamente } \\
\text { não existe }\end{array}$ \\
\hline Recife & $0,021 \%$ & $0,026 \%$ & $0,024 \%$ & $0,032 \%$ & $0,038 \%$ & $0,037 \%$ & $\begin{array}{c}\text { Praticamente } \\
\text { não existe }\end{array}$ \\
\hline Teresina & $0,023 \%$ & $0,021 \%$ & $0,023 \%$ & $0,021 \%$ & $0,030 \%$ & $0,026 \%$ & $\begin{array}{c}\text { Praticamente } \\
\text { não existe }\end{array}$ \\
\hline Natal & $0,008 \%$ & $0,018 \%$ & $0,016 \%$ & $0,012 \%$ & $0,016 \%$ & $0,019 \%$ & $\begin{array}{c}\text { Praticamente } \\
\text { não existe }\end{array}$ \\
\hline Aracaju & $0,032 \%$ & $0,032 \%$ & $0,027 \%$ & $0,027 \%$ & $0,033 \%$ & $0,034 \%$ & $\begin{array}{c}\text { Praticamente } \\
\text { não existe }\end{array}$ \\
\hline
\end{tabular}

Fonte: Resultados da pesquisa.

Os resultados das médias mensais dos ICP's nas capitais nordestinas mantiveram-se abaixo de $1 \%$. Portanto, de acordo com o índice, sugere-se que, para todos os meses de todos os anos em análise, praticamente não há concorrência entre os postos de combustíveis. (Tabela $1 \mathrm{~A}$ ).

É importante salientar que esses resultados devem ser interpretados com cautela, de modo que não se pode concluir com precisão que, nestes mercados, haja a formação de cartel explícito, ou seja, que os postos estejam adotando uma conduta de alinhamento de preços. Conforme ressaltaram Azevedo e Politi (2008), para mercados em que o bem comercializado é homogêneo, como no caso da gasolina comum, a estabilidade de preços é uma evidência de equilíbrio de mercado, seja em cartel ou em concorrência perfeita, não informando a respeito da probabilidade de ocorrência de uma conduta ilícita.

Desse modo, informações adicionais devem ser levadas em consideração para que se tenha maior precisão na avaliação da conduta desses postos revendedores. A Figura 1 abaixo ilustra as margens de comercialização e os coeficientes de variação dos preços de gasolina comum nas revendedoras das capitais nordestinas, de 2010 a 2015. 


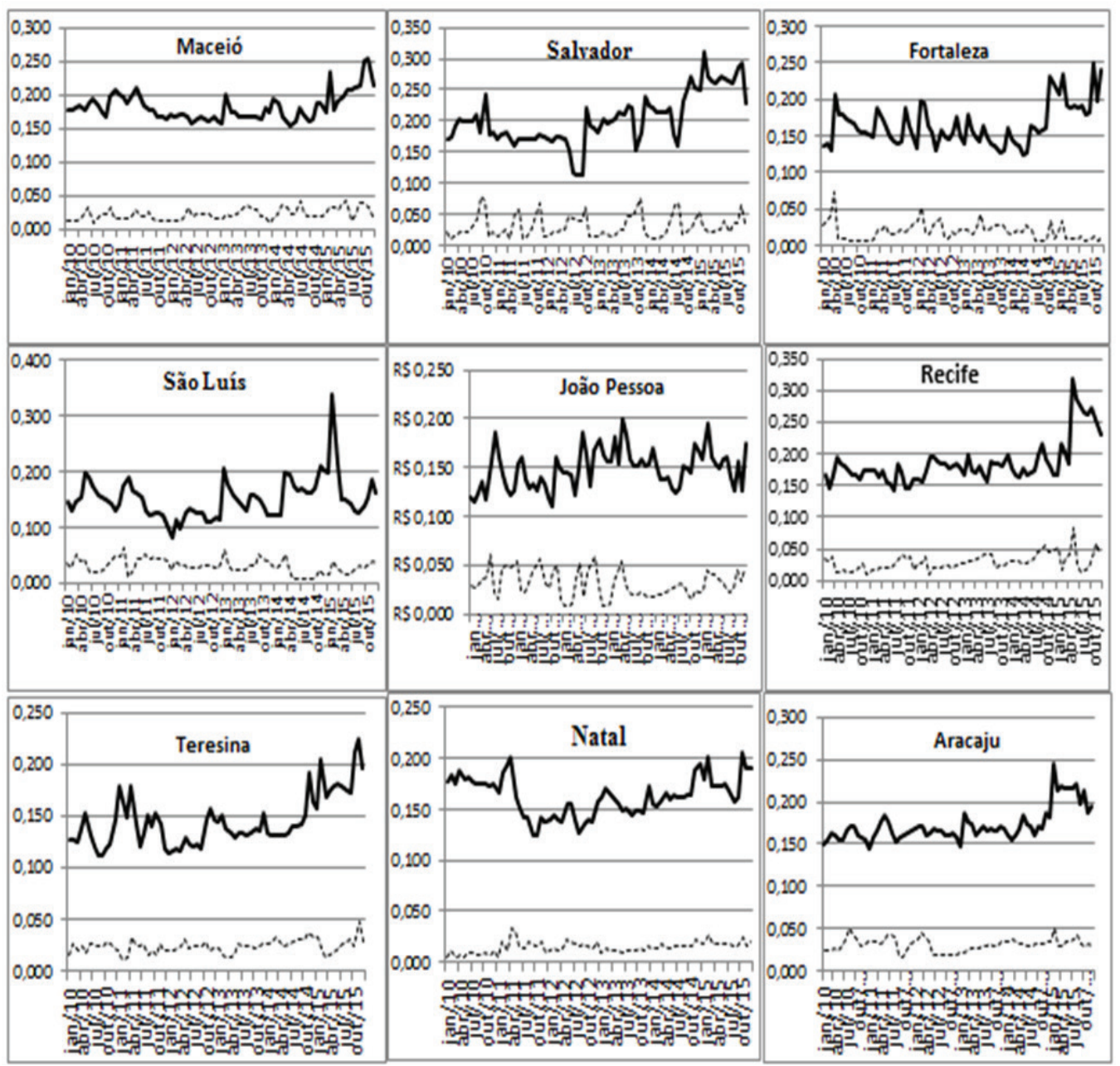

Figura 1 - Margens de comercialização e coeficiente de variação na revenda de gasolina comum nas capitais do Nordeste, de 2010 a 2015.

Conforme ilustra a Figura 1 acima, de maneira geral, a maioria das margens brutas de comercialização apresentou suave tendência ascendente, com presença de picos e vales. A Secretaria de Acompanhamento Econômico (SEAE) associa a hipótese de cartel a não redução da margem de revenda, sugerindo a capacidade de esse se sustentar e, eventualmente, aumentar os preços de revenda em relação aos preços pagos às distribuidoras.

Entretanto, deve-se ressaltar que elevações nas margens podem estar relacionadas a outros fatores como a inclusão de novos serviços que resultariam em 
melhorias na qualidade final do produto ou em decorrência do aumento nos custos de produção. Conforme Azevedo e Politi (2008), as margens de revenda também podem variar em função da escala de produção, dos custos de prestação de serviço, assim como em razão da diferenciação no ponto de venda, não implicando, necessariamente, evidência de exercício de poder de mercado. Assim, ressalta a necessidade da realização de procedimentos que permitam separar casos em que a probabilidade de cartel é mais elevada, distinguindo-os dos casos em que a menor variância dos preços decorre do equilíbrio em concorrência perfeita.

Sobre o comportamento dos coeficientes de variação dos preços, verifica-se que esses mantiveram tendência relativamente mais estável e suficientemente baixa para a maioria dos estados analisados. Porém, conforme mostra a Figura 1, para algumas capitais, a variabilidade desses coeficientes fica evidente pela presença de picos. É importante salientar que, espera-se que margens mais elevadas estejam associadas com dispersões de preços mais baixas, de modo que os postos teriam mais incentivo de praticar preços próximos uns dos outros ou adotar acordos colusivos. Todavia, conforme destacaram Júnior et al. (2008), margens de comercialização maiores podem estar relacionadas a outros fatores que não apenas a dispersão de preços. Shepard (1993) e Lewis (2006) afirmaram que os preços dos combustíveis nos postos e suas margens podem estar associados às variáveis locacionais, ao tipo de contrato com a bandeira distribuidora bem como os custos operacionais, representados, por exemplo, pelo número de funcionários.

Adicionalmente, nesse artigo realizou-se uma análise da estimativa da correlação entre as margens relativas e os coeficientes de variação dos preços da gasolina nos postos de combustíveis nas capitais nordestinas. Os resultados dos coeficientes estimados encontram-se reportados na Tabela 3.

Tabela 3: Resultados das estimações dos coeficientes de correlações entre a margem de comercialização e o coeficiente de variação dos preços na revenda de gasolina

\begin{tabular}{c|c|c}
\hline Capital & Correlação margem bruta e coeficiente de variação & Probabilidade Estatística t \\
\hline Maceió & 0,074 & 0,8166 \\
\hline Salvador & $-1,159$ & 0,0016 \\
\hline Fortaleza & $-1,335$ & 0,0001 \\
\hline São Luís & $-1,352$ & 0,0007 \\
\hline João Pessoa & $-1,057$ & 0,0000 \\
\hline Recife & $-0,354$ & 0,3036 \\
\hline Teresina & $-0,176$ & 0,7428 \\
\hline Natal & $-0,655$ & 0.1326 \\
\hline Aracaju & 1,787 & 0,0000 \\
\hline
\end{tabular}

Fonte: Resultados da pesquisa. 
Os resultados reportados na Tabela 3 mostram que, em Salvador, Fortaleza, São Luís e João Pessoa, os coeficientes de correlação foram negativos e estatisticamente significativos sugerindo que as elevações nas margens de comercialização na revenda estão associadas a menor variância dos preços. Os sinais negativos desses coeficientes indicam que, nessas capitais, há suspeitas de que os postos estariam adotando conduta uniforme, ou seja, onde existe menor dispersão de preços, poderá haver margens mais elevadas.

Por outro lado, em Aracaju, o coeficiente da correlação da margem e variância entre os preços foi positivo e estatisticamente significativo, sugerindo que não há indícios de cartel na revenda de gasolina nessa cidade. Assim, o sinal positivo reflete evidências de concorrência na revenda de gasolina comum no período de análise. As correlações entre as margens e os coeficientes de variação de preços de gasolina nas demais capitais (Recife, Teresina, Natal e Maceió), foram não significativas, ou seja, estatisticamente iguais à zero, sugerindo indícios de ausência de formação de cartel nesses mercados.

Em síntese, baseando-se nas metodologias aplicadas neste artigo, propostas pela ANP e SEAE, é possível inferir que, das nove capitais nordestinas analisadas, quatro delas apresentaram indicativos de comportamento colusivo entre os postos de combustíveis que atuam nesses mercados relevantes geográficos. Nos demais mercados, a hipótese de possibilidade de práticas de conduta colusiva foi rejeitada pelos resultados dos coeficientes de correlação estimados.

\section{Conclusões}

A revenda de gasolina comum apresenta condições propícias à formação de cartéis. Tais características incentivam os agentes desse segmento a optarem por práticas de acordos colusivos, o que, consequentemente, tem implicações negativas sobre o bem- social. Nesse mercado, verifica-se uma série de desafios para a sua regulamentação e fiscalização, pois, os chamados filtros de verificação de formação de carteis, pode implicar em altos custos, os quais nem sempre justificam sua realização, em razão do tamanho do mercado afetado. Usa-se, como exemplo, os mercados de pequenas cidades, onde os custos de uma operação desse porte seriam maiores que os ganhos de bem-estar promovidos pela extinção da falha.

Deste modo, buscou-se aplicar um método pelo qual fosse possível verificar a existência destas falhas de mercado, analisando se ocorria indícios ou não da prática de comportamento colusivo. O mercado relevante para análise foi definido como sendo as nove capitais da região Nordeste do Brasil, pelo fato de em sua maioria terem sidos alvos de denúncias referentes a práticas anticoncorrenciais.

Os resultados dos índices de preços concorrenciais indicaram que, para todos os meses de todos os anos analisados, praticamente não houve concorrência entre os postos de combustíveis. É importante destacar, porém, que esses resultados devem ser analisados com cuidado, uma vez que não se pode inferir com precisão a formação 
de cartéis explícitos, já que o mercado apresenta um produto homogêneo, impossibilitando, à primeira vista, a diferenciação entre um cartel ou um equilíbrio de preços de mercado gerado por uma concorrência quase perfeita. A respeito das margens de comercialização, a maioria delas apresentaram suave tendência ascendente, com a presença de picos e vales. Destaca-se que não houve tendência de comportamento decrescente nas margens calculadas. A hipótese de cartel pode estar associada a não redução da margem de revenda, sob a premissa de sua capacidade de o cartel sustentar e, eventualmente, aumentar os preços e obter aumentos nos lucros. Por último, os resultados das estimativas da correlação entre as margens e o coeficiente de variação de preços mostraram que, em Salvador, Fortaleza, São Luís e João Pessoa, as elevações nas margens de comercialização na revenda pode estar associada a menor variância dos preços. Nesse caso, os sinais negativos e estatisticamente significativos dos coeficientes indicaram que há suspeitas de que os postos estariam adotando conduta uniforme.

Para trabalhos futuros, sugere-se o aprimoramento do modelo para uma maior percepção das características peculiares de cada uma das possíveis ocorrências de mercado, quer seja uma concorrência quase perfeita, quer seja um comportamento colusivo. Ademais, o resultado serve como ponto de partida para o desenvolvimento de modelos mais complexos, capazes de gerar uma necessária estrutura para regulação e inibição de práticas lesivas à sociedade brasileira.

\section{Referências bibliográficas}

AGÊNCIA NACIONAL DE PETRÓLEO - ANP. Levantamento de preços. Disponível e < http://www.anp.gov.br/preco/> Acesso em fev. 2015.

ALVES, D., BUENO, R. L. S. Short-Run, Long-Run and Cross Elasticities of Gasoline Demand in Brazil. Energy Economics. EUA: v. 25, p. 191-199. Março de 2003.

AZEVEDO, P.F.; POLITI, R.B. Na mesma língua: evidências em investigações de cartéis de postos de revenda de combustíveis. IN: MATTOS, C.C.A.A revolução do antitruste no Brasil: a teoria econômica aplicada a casos concretos 2. São Paulo: Singular, 2008.

BURNQUIST, H. L., BACCHI, M. R. P. A Demanda por Gasolina no Brasil: Uma Análise Utilizando Técnicas de Co-integração. In: XL Congresso Brasileiro de Economia e Sociologia Rural, Passo Fundo, RS. Anais do XL Congresso Brasileiro de Economia e Sociologia Rural, 2002.

CONSELHO ADMINISTRATIVO DE DEFESA ECONÔMICA - CADE . (2014) . Cade investiga formação de cartel de postos de combustíveis em Natal (RN). Disponível em: http://www.cade.gov.br/Default.aspx?e85caa7e978c63a075c 292ac86cc. Acesso em 20 de mar de 2016. 
CONSELHO ADMINISTRATIVO DE DEFESA ECONÔMICA - CADE. Combate à carteis na revenda de combustíveis. (2013). Disponível em: http:// www2.camara.leg.br/atividade-legislativa/comissoes/comissoes-Permanentes/ cdc/audiencias-publicas-1/realizadas-em-2013/carteis-de-combustiveis/apresentacao-cade. Acesso em 20 de mar. 2016.

CARLTON \& PERLOFF, D. W. \& PERLOFF, J.M. Modern Industrial Organization. Harper Collins College Publisher, 1994.

DIEHL, D. ; ANDRIOLLI M.; BACCHI, M. R.P.. Elasticidades-renda das despesas com álcool e gasolina para automóveis e comerciais leves no Brasil em 20022003. In: XLV CONGRESSO BRASILEIRO DE ECONOMIA E SOCIOLOGIA RURAL, 2007, Londrina, PR. Anais... Brasília, 2007. 1 CD-ROM.

FORGIONI, P.A. Contrato de distribuição. São Paulo: RT, 2005.

FETTER, S.K. Detecção de cartéis por marcadores de colusão. Dissertação (mestrado) - Escola de Economia de São Paulo, Fundação Getúlio Vargas, 2012. p. 72.

FREITAS, T. A.; NETO, G. B. Análise cross-section da dispersão dos preços para sinalização de práticas anticompetitivas no mercado de combustíveis. Revista Sinergia, Rio Grande, 15(2): 33-48, 2011.

GÜLEN, S. G. Is OPEC a Cartel? Evidence from cointegration and causaliy tests. Boston: Department of Economics of the Boston College, 1996. (WorkingPaper, n. 318). Disponível em: http://fmwww.bc.edu Acesso em: 12 de mar 2016.

HARRINGTON Jr., J.E. How Do Cartels Operate?.Foundations and Trends in Microeconomics, v. 2, n. 1 p. 1-105, 2006. crossref https://doi.org/10.1561/0700000021

INSTITUTO DE CIÊNCIAS ECONÔMICAS, ADMINISTRATIVAS E CONTÁBEIS - ICEAC. Relatório sobre os preços dos combustíveis nas capitais brasileiras e nas cidades gaúchas - Agosto de 2014. Disponível em: < http: www.cip. furg.br. Acesso em 03 mar. 2016.

JUNIOR et. all (2008). Lucratividade, Forma Contratual e Características do Varejo de Gasolina Brasileiro. Universidade Federal de Juiz de Fora - Programa de Pós-Graduação em Economia Aplicada. Juiz de Fora - Minas Gerais. Disponível em: http://www. ufjf.br/poseconomia/files/2010/01/TD-004-Luciano.pdf. Acesso em 04/03/2016.

MAGGI, B. O..O cartel e os seus efeitos no âmbito da responsabilidade civil. 233 p. Dissertação (Mestrado)- Faculdade de Direito, Universidade de São Paulo, São Paulo, 2010. 
NAPPO, M.. A demanda por gasolina no Brasil: Uma avaliação de suas elasticidades após a introdução dos carros biocombustível. 61p. Dissertação (Mestrado) - Escola de Economia de São Paulo, Fundação Getúlio Vargas - FGV, São Paulo, 2007.

ROPPA, B. F. Evolução do Consumo de Gasolina no Brasil e suas Elasticidades: 1973 a 2003. Rio de Janeiro: Universidade Federal do Rio de Janeiro, 2005. Monografia de Graduação - Curso em Ciências Econômicas do Instituto de Economia da Universidade Federal do Rio de Janeiro.

SECRETARIA DE DIREITO ECONÔMICO. Combates a carteis e programa de leniência. (2009) 3a . Ed. Disponível em :< http: http://www.cade.gov.br/upload/ Cartilha\%20Leniencia\%20SDE_CADE.pdf. Acesso em 11 de mar. 2016.

SHEPARD, A. (1993). Contractual Form, Retail Price, and Asset Characteristics in Gasoline Retailing. The RAND Journal of Economics, v. 24, 58-77, 1993. crossref https://doi.org/10.2307/2555953

VASCONCELOS, S.P.; MATTOS, R.S.. Symmetric transmission of prices in there tail gasoline market in Brazil. Energy Economics, v. 43, p. 11-21, 2014. crossref https://doi.org/10.1016/j.eneco.2014.02.002

VASCONCELOS, S. P.; VASCONCELOS, C. F. Análise do comportamento estratégico em preços no mercado de gasolina brasileiro: modelando volatilidade. Revista Análise Econômica, Porto Alegre, v. 26, n. 50, p. 207-222 setembro de 2008.

VASCONCELOS, S. P.; VASCONCELOS, C. F. Ferramentas de detecção dos acordos em preços no mercado de gasolina a varejo. In: ENCONTRO NACIONAL DE ECONOMIA, 37., 2009, Foz do Iguaçu. Anais..., Foz do Iguaçu: ANPEC, 2009.

VASCONCELOS, S. P.; VASCONCELOS, C. F. Investigações e obtenção de provas de cartel: porque e como observar paralelismo de conduta. Ensaios FEE, v. 26, n. 2. 2005.

Recebido em 07.04.16

Aprovado em 30.11.16 


\section{Anexo A}

Tabela 1 A: Índices Concorrenciais de Preços mensais (em \%) nas capitais do Nordeste, 2010 a 2015

\begin{tabular}{|c|c|c|c|c|c|c|c|c|c|}
\hline Mês/ano & Maceió & Salvador & Fortaleza & São Luis & João Pessoa & Recife & Teresina & Natal & Aracaju \\
\hline $\mathrm{jan} / 10$ & 0,012 & 0,023 & 0,026 & 0,034 & 0,028 & 0,036 & 0,016 & 0,006 & 0,024 \\
\hline $\mathrm{fev} / 10$ & 0,015 & 0,011 & 0,035 & 0,026 & 0,026 & 0,031 & 0,026 & 0,012 & 0,025 \\
\hline mar/10 & 0,012 & 0,019 & 0,039 & 0,054 & 0,031 & 0,038 & 0,019 & 0,006 & 0,024 \\
\hline $\mathrm{abr} / 10$ & 0,015 & 0,022 & 0,073 & 0,039 & 0,037 & 0,012 & 0,025 & 0,006 & 0,027 \\
\hline mai/10 & 0,023 & 0,020 & 0,008 & 0,043 & 0,039 & 0,014 & 0,019 & 0,006 & 0,025 \\
\hline jun/10 & 0,031 & 0,023 & 0,010 & 0,022 & 0,060 & 0,017 & 0,026 & 0,009 & 0,028 \\
\hline $\mathrm{jul} / 10$ & 0,010 & 0,027 & 0,008 & 0,018 & 0,021 & 0,013 & 0,026 & 0,008 & 0,038 \\
\hline ago/10 & 0,016 & 0,044 & 0,007 & 0,021 & 0,016 & 0,013 & 0,024 & 0,006 & 0,051 \\
\hline set/10 & 0,023 & 0,079 & 0,006 & 0,022 & 0,046 & 0,017 & 0,023 & 0,007 & 0,043 \\
\hline out $/ 10$ & 0,024 & 0,072 & 0,006 & 0,034 & 0,049 & 0,022 & 0,029 & 0,009 & 0,038 \\
\hline nov/10 & 0,033 & 0,014 & 0,007 & 0,039 & 0,048 & 0,029 & 0,026 & 0,006 & 0,028 \\
\hline $\mathrm{dez} / 10$ & 0,017 & 0,022 & 0,007 & 0,048 & 0,050 & 0,009 & 0,022 & 0,012 & 0,030 \\
\hline $\mathrm{jan} / 11$ & 0,015 & 0,014 & 0,007 & 0,047 & 0,054 & 0,017 & 0,020 & 0,006 & 0,034 \\
\hline $\mathrm{fev} / 11$ & 0,018 & 0,023 & 0,008 & 0,064 & 0,024 & 0,017 & 0,012 & 0,020 & 0,033 \\
\hline mar/11 & 0,015 & 0,027 & 0,021 & 0,013 & 0,022 & 0,022 & 0,014 & 0,011 & 0,034 \\
\hline $\mathrm{abr} / 11$ & 0,020 & 0,013 & 0,021 & 0,022 & 0,030 & 0,021 & 0,033 & 0,033 & 0,032 \\
\hline mai/11 & 0,031 & 0,053 & 0,029 & 0,043 & 0,042 & 0,022 & 0,027 & 0,031 & 0,035 \\
\hline jun/11 & 0,020 & 0,059 & 0,017 & 0,042 & 0,050 & 0,022 & 0,024 & 0,016 & 0,043 \\
\hline jul/11 & 0,021 & 0,011 & 0,016 & 0,051 & 0,056 & 0,028 & 0,025 & 0,013 & 0,043 \\
\hline ago/11 & 0,025 & 0,013 & 0,017 & 0,045 & 0,030 & 0,035 & 0,015 & 0,020 & 0,039 \\
\hline set/11 & 0,017 & 0,020 & 0,020 & 0,047 & 0,027 & 0,041 & 0,019 & 0,019 & 0,019 \\
\hline out/11 & 0,012 & 0,052 & 0,020 & 0,045 & 0,044 & 0,036 & 0,014 & 0,017 & 0,016 \\
\hline nov/11 & 0,013 & 0,069 & 0,023 & 0,045 & 0,049 & 0,037 & 0,027 & 0,020 & 0,024 \\
\hline $\mathrm{dez} / 11$ & 0,012 & 0,015 & 0,032 & 0,039 & 0,015 & 0,018 & 0,019 & 0,010 & 0,031 \\
\hline $\mathrm{jan} / 12$ & 0,014 & 0,014 & 0,034 & 0,025 & 0,008 & 0,028 & 0,019 & 0,011 & 0,034 \\
\hline $\mathrm{fev} / 12$ & 0,012 & 0,022 & 0,053 & 0,042 & 0,009 & 0,029 & 0,020 & 0,013 & 0,038 \\
\hline $\mathrm{mar} / 12$ & 0,014 & 0,021 & 0,019 & 0,031 & 0,010 & 0,038 & 0,022 & 0,012 & 0,045 \\
\hline $\mathrm{abr} / 12$ & 0,018 & 0,024 & 0,016 & 0,030 & 0,036 & 0,011 & 0,024 & 0,014 & 0,038 \\
\hline mai/12 & 0,033 & 0,026 & 0,027 & 0,028 & 0,051 & 0,021 & 0,030 & 0,022 & 0,033 \\
\hline jun/12 & 0,020 & 0,045 & 0,035 & 0,027 & 0,018 & 0,019 & 0,021 & 0,021 & 0,018 \\
\hline jul/12 & 0,023 & 0,042 & 0,037 & 0,026 & 0,042 & 0,021 & 0,024 & 0,019 & 0,019 \\
\hline ago/12 & 0,025 & 0,039 & 0,011 & 0,033 & 0,053 & 0,023 & 0,025 & 0,016 & 0,018 \\
\hline set/12 & 0,023 & 0,038 & 0,010 & 0,033 & 0,059 & 0,025 & 0,024 & 0,018 & 0,018 \\
\hline out/12 & 0,023 & 0,062 & 0,017 & 0,033 & 0,029 & 0,020 & 0,028 & 0,016 & 0,019 \\
\hline nov/12 & 0,017 & 0,015 & 0,015 & 0,028 & 0,009 & 0,024 & 0,020 & 0,013 & 0,019 \\
\hline $\mathrm{dez} / 12$ & 0,015 & 0,013 & 0,022 & 0,029 & 0,009 & 0,027 & 0,022 & 0,020 & 0,019 \\
\hline
\end{tabular}


(continuação)

\begin{tabular}{|c|c|c|c|c|c|c|c|c|c|}
\hline Mês/ano & Maceió & Salvador & Fortaleza & São Luis & João Pessoa & Recife & Teresina & Natal & Aracaju \\
\hline $\mathrm{jan} / 13$ & 0,016 & 0,013 & 0,022 & 0,060 & 0,010 & 0,027 & 0,023 & 0,010 & 0,020 \\
\hline fev/13 & 0,024 & 0,020 & 0,023 & 0,030 & 0,033 & 0,030 & 0,015 & 0,014 & 0,022 \\
\hline $\operatorname{mar} / 13$ & 0,020 & 0,017 & 0,015 & 0,024 & 0,044 & 0,033 & 0,013 & 0,012 & 0,024 \\
\hline $\mathrm{abr} / 13$ & 0,024 & 0,016 & 0,024 & 0,024 & 0,053 & 0,035 & 0,014 & 0,011 & 0,026 \\
\hline mai/13 & 0,026 & 0,019 & 0,042 & 0,023 & 0,030 & 0,038 & 0,015 & 0,011 & 0,025 \\
\hline jun/13 & 0,033 & 0,024 & 0,020 & 0,023 & 0,021 & 0,042 & 0,026 & 0,010 & 0,027 \\
\hline $\mathrm{jul} / 13$ & 0,037 & 0,025 & 0,022 & 0,031 & 0,021 & 0,042 & 0,025 & 0,011 & 0,029 \\
\hline ago/13 & 0,028 & 0,047 & 0,023 & 0,030 & 0,020 & 0,043 & 0,025 & 0,011 & 0,029 \\
\hline set/13 & 0,031 & 0,046 & 0,028 & 0,052 & 0,022 & 0,021 & 0,024 & 0,011 & 0,031 \\
\hline out/13 & 0,018 & 0,060 & 0,028 & 0,046 & 0,019 & 0,023 & 0,022 & 0,013 & 0,030 \\
\hline nov/13 & 0,019 & 0,074 & 0,028 & 0,039 & 0,018 & 0,023 & 0,023 & 0,011 & 0,029 \\
\hline $\mathrm{dez} / 13$ & 0,011 & 0,020 & 0,018 & 0,030 & 0,018 & 0,027 & 0,025 & 0,015 & 0,035 \\
\hline jan/14 & 0,019 & 0,015 & 0,017 & 0,029 & 0,019 & 0,030 & 0,027 & 0,013 & 0,035 \\
\hline fev/14 & 0,022 & 0,012 & 0,019 & 0,033 & 0,020 & 0,033 & 0,028 & 0,013 & 0,033 \\
\hline mar/14 & 0,035 & 0,011 & 0,020 & 0,051 & 0,023 & 0,030 & 0,032 & 0,018 & 0,036 \\
\hline $\mathrm{abr} / 14$ & 0,032 & 0,013 & 0,018 & 0,022 & 0,025 & 0,026 & 0,028 & 0,016 & 0,034 \\
\hline mai/14 & 0,024 & 0,017 & 0,027 & 0,008 & 0,026 & 0,029 & 0,023 & 0,015 & 0,032 \\
\hline jun/14 & 0,022 & 0,043 & 0,020 & 0,009 & 0,029 & 0,030 & 0,027 & 0,016 & 0,031 \\
\hline $\mathrm{jul} / 14$ & 0,043 & 0,066 & 0,008 & 0,009 & 0,031 & 0,034 & 0,028 & 0,015 & 0,030 \\
\hline ago/14 & 0,024 & 0,067 & 0,005 & 0,007 & 0,030 & 0,046 & 0,030 & 0,016 & 0,030 \\
\hline set/14 & 0,020 & 0,018 & 0,006 & 0,009 & 0,020 & 0,049 & 0,031 & 0,016 & 0,031 \\
\hline out/14 & 0,020 & 0,021 & 0,008 & 0,013 & 0,015 & 0,055 & 0,031 & 0,015 & 0,031 \\
\hline nov/14 & 0,021 & 0,027 & 0,033 & 0,023 & 0,025 & 0,044 & 0,038 & 0,022 & 0,033 \\
\hline $\mathrm{dez} / 14$ & 0,019 & 0,042 & 0,009 & 0,015 & 0,023 & 0,048 & 0,033 & 0,020 & 0,035 \\
\hline $\mathrm{jan} / 15$ & 0,021 & 0,055 & 0,017 & 0,017 & 0,025 & 0,051 & 0,032 & 0,018 & 0,035 \\
\hline fev/15 & 0,033 & 0,029 & 0,034 & 0,042 & 0,046 & 0,018 & 0,022 & 0,027 & 0,050 \\
\hline $\mathrm{mar} / 15$ & 0,032 & 0,021 & 0,009 & 0,028 & 0,041 & 0,037 & 0,012 & 0,017 & 0,029 \\
\hline $\mathrm{abr} / 15$ & 0,029 & 0,021 & 0,009 & 0,018 & 0,040 & 0,042 & 0,015 & 0,018 & 0,029 \\
\hline mai/15 & 0,040 & 0,024 & 0,009 & 0,018 & 0,037 & 0,083 & 0,017 & 0,018 & 0,034 \\
\hline jun/15 & 0,042 & 0,025 & 0,008 & 0,018 & 0,033 & 0,023 & 0,021 & 0,018 & 0,034 \\
\hline jul/15 & 0,012 & 0,040 & 0,011 & 0,024 & 0,026 & 0,014 & 0,027 & 0,018 & 0,036 \\
\hline ago/15 & 0,023 & 0,022 & 0,007 & 0,030 & 0,022 & 0,017 & 0,029 & 0,016 & 0,042 \\
\hline set/15 & 0,039 & 0,036 & 0,009 & 0,026 & 0,027 & 0,022 & 0,030 & 0,015 & 0,033 \\
\hline out/15 & 0,041 & 0,036 & 0,012 & 0,030 & 0,046 & 0,038 & 0,025 & 0,025 & 0,030 \\
\hline nov/15 & 0,032 & 0,066 & 0,006 & 0,041 & 0,035 & 0,058 & 0,048 & 0,015 & 0,032 \\
\hline $\mathrm{dez} / 15$ & 0,020 & 0,038 & 0,011 & 0,035 & 0,048 & 0,042 & 0,029 & 0,021 & 0,029 \\
\hline
\end{tabular}

Fonte: Resultados da pesquisa. 
